\title{
The anesthetic effects of intramuscular alfaxalone in dogs premedicated with low-dose medetomidine and/or butorphanol
}

\author{
Keiko KATO ${ }^{1)}$, Takaharu ITAMI 1)*, Ken NOMOTO'1), Yusuke ENDO'1), Jun TAMURA ${ }^{1)}$, \\ Norihiko OYAMA ${ }^{1)}$, Tadashi SANO ${ }^{2)}$ and Kazuto YAMASHITA ${ }^{1)}$ \\ 1)Department of Small Animal Clinical Sciences, School of Veterinary Medicine, Rakuno Gakuen University, \\ Ebetsu, Hokkaido 069-8591, Japan \\ 2) Department of Veterinary Nursing Sciences, School of Veterinary Medicine, Rakuno Gakuen University, \\ Ebetsu, Hokkaido 069-8591, Japan
}

J. Vet. Med. Sci.

83(1): 53-61, 2021

doi: 10.1292/jvms.20-0330

Received: 1 June 2020

Accepted: 28 October 2020

Advanced Epub:

13 November 2020

\begin{abstract}
We aimed to evaluate the induction, anesthesia, and cardiorespiratory effects of intramuscular (IM) anesthetic protocol with alfaxalone following premedication with low-dose medetomidine, butorphanol, or a combination of both (medetomidine-butorphanol) in dogs. Six healthy beagles were administered $1,2.5$, or $5 \mathrm{mg} / \mathrm{kg}$ alfaxalone IM following premedication with low-dose medetomidine ( $5 \mathrm{\mu g} / \mathrm{kg}$; MA-IM), butorphanol $(0.3 \mathrm{mg} / \mathrm{kg}$; BA-IM), or medetomidinebutorphanol ( $5 \mu \mathrm{g} / \mathrm{kg}$ and $0.3 \mathrm{mg} / \mathrm{kg}$, respectively; MBA-IM). Each dog received 9 treatments with minimum 7-day washout period between treatments. Dogs were allowed to breath room air during anesthetic induction. We attempted endotracheal intubation after alfaxalone administration. Alfaxalone produced a dose-dependent anesthetic effect in each anesthetic protocol. Intubation was achieved in 4 out of 6 dogs that received MA-IM and BA-IM with 2.5 $\mathrm{mg} / \mathrm{kg}$ alfaxalone and in all dogs that received MBA-IM with $1,2.5$, and $5 \mathrm{mg} / \mathrm{kg}$ alfaxalone. The median durations [minimum-maximum] of accepting intubation were 79 [0-89], 97 [84-120], and 117 [84-217] min, respectively. Hypotension (mean arterial blood pressure $<60 \mathrm{mmHg}$ ) did not develop, but bradycardia (heart rate $<60$ beats $/ \mathrm{min}$ ) was observed in all dogs that received the MA-IM and MBA-IM protocols. Severe hypoxemia (percutaneous arterial oxygen saturation $<90 \%$ ) developed in 2 dogs that received MBA-IM with $5 \mathrm{mg} / \mathrm{kg}$ alfaxalone. We consider that the MA-IM and BA-IM protocols with $\geq 2.5 \mathrm{mg} / \mathrm{kg}$ alfaxalone and the MBA-IM protocol with $1-2.5 \mathrm{mg} /$ $\mathrm{kg}$ alfaxalone could provide clinically useful and effective anesthesia without causing severe cardiorespiratory depression in healthy dogs.
\end{abstract}

KEY WORDS: alfaxalone, butorphanol, dog, intramuscular anesthesia, medetomidine

General anesthesia is an indispensable medical procedure, and injectable anesthetics are commonly used in modern veterinary practice. Subcutaneous or intramuscular (IM) injectable anesthetic agents are very important and useful, particularly when intravenous (IV) administration is difficult in fractious, fearful, or excited patients. IM administration of ketamine in combination with benzodiazepines, $\alpha_{2}$-adrenoceptor agonists ( $\alpha_{2}$-agonists), and/or opioids has been widely used to induce general anesthesia in dogs because of its availability and efficacy $[7,26]$. However, ketamine is legally controlled, and its usage is severely restricted in many countries.

Alfaxalone is a synthetic neuroactive steroid molecule that causes neuro-depression and muscular relaxation associated with the gamma-aminobutyric acid $\mathrm{A}\left(\mathrm{GABA}_{\mathrm{A}}\right)$ receptor in the central nervous system $[2,4]$. In the past decade, a new alfaxalone formulation that is solubilized with 2-hydroxypropyl-beta-cyclodextrin has been approved and is used as an IV anesthetic agent for dogs and cats in many countries because of its smooth induction, rapid recovery, and minimal cardiorespiratory depression [4, 9, 14]. It was also reported that IM administration of 7.5 to $10 \mathrm{mg} / \mathrm{kg}$ alfaxalone produced anesthetic effects that enabled endotracheal intubation with mild cardiorespiratory depression in dogs; however, some undesirable events, including transient muscular tremors and ataxia, were observed during recovery [24]. In addition, the clinical application of anesthetic IM alfaxalone may be difficult due to the large dosage volumes $(0.75-1 \mathrm{ml} / \mathrm{kg})[24]$.

The use of anesthetics with different mechanisms of action may reduce the dose or side effects of individual anesthetics. In

*Correspondence to: Itami, T.: t-itami@rakuno.ac.jp

(Supplementary material: refer to PMC https://www.ncbi.nlm.nih.gov/pmc/journals/2350/)

O2021 The Japanese Society of Veterinary Science

This is an open-access article distributed under the terms of the Creative Commons Attribution Non-Commercial No Derivatives (by-nc-nd) License. (CC-BY-NC-ND 4.0: https://creativecommons.org/licenses/by-nc-nd/4.o/) 
recent years, two prospective trials have reported that small doses of combined IM administration with medetomidine, butorphanol, and alfaxalone provide an anesthetic effect that could be clinically applied in dogs [11,23]. Lee et al. [11] reported that IM co-administration of $10 \mu \mathrm{g} / \mathrm{kg}$ medetomidine, $0.1 \mathrm{mg} / \mathrm{kg}$ butorphanol, and $1.5 \mathrm{mg} / \mathrm{kg}$ alfaxalone induced an anesthetic effect that ensured the maintenance of endotracheal intubation with substantial cardiorespiratory depression in dogs. Tamura et al. [23] reported that IM co-administration of $2.5 \mu \mathrm{g} / \mathrm{kg}$ medetomidine, $0.25 \mathrm{mg} / \mathrm{kg}$ butorphanol, and $2.5 \mathrm{mg} / \mathrm{kg}$ alfaxalone allowed endotracheal intubation without severe cardiorespiratory depression in dogs.

Medetomidine is a highly selective $\alpha_{2}$-agonist that is commonly used as premedication before the induction of anesthesia to provide sedation and analgesia by causing dose-dependent cardiovascular depression (bradycardia) and a decrease in cardiac output $[10,15,20]$. In addition, medetomidine should not be used in dogs with heart disorders, such as mitral valve regurgitation, because of its strong vasoconstrictor effects [18]. Meanwhile, butorphanol is a synthetic opioid with $\kappa$-agonist and $\mu$-antagonist properties that can be used to provide sedation and analgesia in dogs, with minimal cardiopulmonary depression [25]. Alternatively, since the analgesic effect of butorphanol has a ceiling effect [16], $\mu$-agonists, such as fentanyl or morphine, could not be added as rescue analgesia during surgery even if the dogs feel more pain [17].

For the reasons just provided, the use of medetomidine or butorphanol may be avoided in some clinical situations. However, as far as we know, no study has examined the sedative effects of a clinically appropriate dose of alfaxalone with medetomidinebutorphanol, medetomidine, or butorphanol. Herein, we aimed to evaluate the induction, anesthesia, cardiorespiratory effects, and recovery of IM anesthetic protocol with different doses $(1,2.5$, and $5 \mathrm{mg} / \mathrm{kg})$ of alfaxalone following premedication with low-dose medetomidine $(5 \mu \mathrm{g} / \mathrm{kg})$ alone, butorphanol $(0.3 \mathrm{mg} / \mathrm{kg})$ alone, or a combination of both (medetomidine-butorphanol) in dogs.

\section{MATERIALS AND METHODS}

\section{Experimental animals}

We used 6 intact adult beagles (age, 1 year; male, 3; female, 3; body weight: median, $9.9 \mathrm{~kg}$; range, $7.3-12.3 \mathrm{~kg}$ ) in the present study. The dogs were in good to excellent health based on physical examination, blood cell count, and serum biochemical examination. Food was withheld from the dogs for $12 \mathrm{hr}$ before each drug treatment, but they were allowed free access to water. The dogs were cared for according to the principles of the Guide for the Care and Use of Laboratory Animals prepared by Rakuno Gakuen University. The Animal Care and Use Committee of Rakuno Gakuen University approved the present study design (approval no. VH14B10).

\section{Study design}

We used a randomized crossover study design. All dogs were assigned 9 occasions by a computer-generated randomized table and were administered 9 different anesthetic treatments with a 7-day washout period between each treatment. The dogs were anesthetized with 1, 2.5, or $5 \mathrm{mg} / \mathrm{kg}$ alfaxalone IM (Alfaxan; Meiji Seika Pharma, Co., Ltd., Tokyo, Japan) 15 min after premedication with $5 \mu \mathrm{g} / \mathrm{kg}$ medetomidine IM (Domitor; Nippon Zenyaku Kogyo, Co., Ltd., Fukushima, Japan) (MA-IM anesthetic protocol: MA-1, MA-2.5, or MA-5 treatment, respectively), $0.3 \mathrm{mg} / \mathrm{kg}$ butorphanol (Vetorphal; Meiji Seika Pharma, Co., Ltd.) (BA-IM anesthetic protocol: BA-1, BA-2.5, or BA-5 treatment, respectively), or medetomidine-butorphanol (dose same as above; MBA-IM anesthetic protocol: MBA-1, MBA-2.5, or MBA-5 treatment, respectively) on each occasion. Each IM premedication dose was injected into the right dorsal lumbar muscle of the dogs using a 23-gauge, 1 -inch $(2.54 \mathrm{~cm})$ needle (TOP injection needle; TOP Co., Ltd., Tokyo, Japan) and a 1-ml plastic injection syringe (Nipro syringe; Nipro Co., Ltd., Osaka, Japan). Each IM alfaxalone dose was injected in a similar manner using a 5- or 10-ml plastic injection syringe (Nipro syringe; Nipro Co., Ltd.). The dogs were allowed to breathe room air spontaneously throughout the experiment and were intubated with an endotracheal tube (inner diameter $7.5 \mathrm{~mm}$ endotracheal tube with cuff; Fuji Systems Corp., Tokyo, Japan) when possible. Extubation was performed when the dogs recovered their laryngeal reflex. The anesthetic and cardiorespiratory effects were evaluated in the dogs before premedication (baseline) and at 0 (i.e., 15 min after premedication and just before IM administration of alfaxalone), 5, 10, 15, 20, 30, 45, 60, 90, 120, and $180 \mathrm{~min}$ after the IM administration of alfaxalone.

\section{Evaluation of anesthetic effect}

The anesthetic effect was evaluated by the quality of anesthetic induction (including the ease of endotracheal intubation), quality of recovery from anesthesia, and the degree of neuro-depression. The qualities of anesthetic induction and recovery were assessed using numerical scoring systems (1: poor, 2: moderately smooth, 3: quite smooth, 4: very smooth) previously used in dogs [22]. Neuro-depression was subjectively evaluated by a composite measurement scoring system previously used in dogs [5, 23, 27]. The scoring system comprised 6 categories: spontaneous posture (0-4), placement on side ( $0-3)$, response to noise (0-4), jaw relaxation (0-2), general attitude (0-3), and nociceptive response to toe-pinch (0-3). The total neuro-depressive score was calculated as the sum of the scores of the 6 categories, with a maximum score of 19. A well-trained observer (K.N.), who was blind to the anesthetic treatments, evaluated the anesthetic effect of the treatments using these scoring systems. In addition, the following time durations were recorded: time between alfaxalone administration and onset of lateral recumbency (time until onset to lateral recumbency; $\mathrm{sec}$ ); time between alfaxalone administration and achievement of endotracheal intubation (time until intubation; min); time between achievement of intubation and removal of endotracheal tube (duration of intubation; min); time between onset of lateral recumbency and head lift (duration of lateral recumbency; min); time between head lift and standing position (standing time; min). 


\section{Measurements of cardiorespiratory valuables}

Lead II electrocardiography (ECG), rectal temperature $\left(\mathrm{RT} ;{ }^{\circ} \mathrm{C}\right)$, heart rate (HR; beats/min), respiration rate (RR; breaths $\left./ \mathrm{min}\right)$, and non-invasive mean arterial blood pressure (NMABP; $\mathrm{mm} \mathrm{Hg}$ ) were recorded before IM premedication and every 5 min until the dogs could lift their head or 180 min after alfaxalone administration. In addition, percutaneous arterial oxygen saturation $\left(\mathrm{SpO}_{2} ; \%\right)$ and partial pressure of end-expiratory carbon dioxide $\left(\mathrm{ETCO}_{2} ; \mathrm{mm} \mathrm{Hg}\right)$ were measured after alfaxalone administration. RT was measured using a veterinary digital thermometer (Thermoflex TF8731; Astec Co., Ltd., Tokyo, Japan). ECG, HR, RR, $\mathrm{ETCO}_{2}$, and $\mathrm{SpO}_{2}$ were measured using a patient monitoring system (DS-7210 System; Fukuda Denshi Co., Ltd., Tokyo, Japan). If necessary, HR and RR were additionally measured with a stethoscope and by observing thoracic movements, respectively. $\mathrm{ETCO}_{2}$ was measured in dogs that achieved endotracheal intubation using mainstream capnography (Mainstream Unit MGU-721; Fukuda Denshi Co., Ltd.). $\mathrm{SpO}_{2}$ was measured using an $\mathrm{SpO}_{2}$ probe (Nellcor Sensor DS-100A; Fukuda Denshi Co., Ltd.) placed on the tongue. NMABP was measured using a veterinary oscillometer blood pressure device (petMAP graphic; Atom Vets Medical Co., Ltd., Kyoto, Japan) and a veterinary pressure cuff (Clitter cuff; Atom Vets Medical Co., Ltd.) with a width of approximately $40 \%$ of the circumference of the measuring site; it was placed around the clipped tail base of each dog.

\section{Statistical analysis}

Data were reported as the number of dogs in each anesthetic treatment or the median [minimum-maximum] calculated from the total of 6 dogs. The number of dogs that showed lateral recumbency and accepted intubation was compared by Fisher's exact test. The total neuro-depressive score, RT, HR, RR, and NMABP obtained before premedication and at 0 min were statistically compared using the Friedman test. The data obtained after the IM administration of alfaxalone were statistically compared among the different anesthetic protocols, i.e., those using different IM doses of alfaxalone with the same IM premedication and those using different IM premedications with the same IM dose of alfaxalone. Changes in the total neuro-depressive score and the scores of the 6 categories, qualities of anesthesia induction and recovery, and cardiorespiratory valuables were analyzed by the Friedman test. The Scheffe test was used as post-hoc test for the same. The times until onset of lateral recumbency and intubation, durations of intubation and lateral recumbency, and standing times were analyzed by the Kruskal-Wallis and Steel-Dwass tests to analyze data with missing values because some dogs were recovered. All analyses were conducted with a proprietary software package (BellCurve for Excel; Social Survey Research Information Co., Ltd., Tokyo, Japan). A $P$-value $<0.05$ was considered statistically significant.

\section{RESULTS}

\section{Sedative and cardiorespiratory effects produced by premedication}

Marked sedation that made the dogs relaxed and positioned in lateral recumbency was observed 15 min after drug administration (at $0 \mathrm{~min}$ ) in 15 out of 18 occasions (83.3\%) of medetomidine-butorphanol premedication. Meanwhile, premedication with either medetomidine or butorphanol alone produced inadequate sedation that did not produce lateral recumbency in any dog. Marked salivation was observed in $3(16.7 \%)$ of 18 occasions of butorphanol premedication. No dog exhibited vomiting after any form of premedication.

Changes in the total neuro-depression score, RT, HR, RR, and NMABP produced by each premedication are summarized in Table 1. The total neuro-depression score increased to a median score $\geq 11.5$ at 0 min in medetomidine-butorphanol premedication, whereas the median scores were $\leq 2.5$ and $\leq 4$ at $0 \mathrm{~min}$ in the medetomidine-alone and butorphanol-alone protocols, respectively. There was no significant change in the RT and NMABP after each premedication. HR decreased significantly to $<60$ beats $/ \mathrm{min}$ after the medetomidine-alone and medetomidine-butorphanol protocols $(P<0.001$ in both). In addition, RR decreased significantly to $<18$ breaths/min after medetomidine-butorphanol premedication $(P=0.022)$.

\section{Anesthetic effect produced by IM alfaxalone after premedication}

Painful or uncomfortable reactions, such as aggression, avoidance, escape, screaming, and yelping, were observed in 2 dogs that received MA-1, MA-2.5, MA-5, and BA-1 treatments, respectively, and in 1 dog that received BA-5 and MBA-5 treatments, respectively.

Except for 2 dogs who received BA-1 treatment, the rest of the dogs were positioned in lateral recumbency after alfaxalone administration. Endotracheal intubation was achieved in 4 dogs that received MA-2.5, BA-2.5, and BA-5 treatments and all dogs that received MA-5, MBA-1, MBA-2.5, and MBA-5 treatments. The median scores [minimum-maximum] of the quality of anesthetic induction were $1[1,1], 2[1,2]$, and $2[2,2]$ for the MA-1, MA-2.5, and MA-5 treatments, respectively; $1[1,1]$, $2[1,2]$, and $2[1,2]$ for the BA-1, BA-2.5, and BA-5 treatments, respectively; and $2[1-3], 2[2,3]$, and 4 [2-4] for the MBA1 , MBA-2.5, and MBA-5 treatments, respectively. When comparing the protocols using different doses of alfaxalone with the same premedication, significantly higher scores for the quality of anesthetic induction were detected in MA-5 than that in MA-1 $(P=0.011)$ and in MBA-5 treatment than that in MBA-1 $(P=0.024)$. When comparing the anesthetic treatments that used different premedications with the same dose of alfaxalone, the quality of anesthetic induction was higher in MBA-1 than that in MA-1 $(P=0.024)$ and BA-1 $(P=0.024)$ and also in MBA-5 than that in BA-5 $(P=0.018)$.

Table 2 summarizes the time until onset of lateral recumbency, time until intubation, duration of intubation, duration of lateral recumbency, and standing time. The time until onset of lateral recumbency and time until intubation were shorter in the MBA groups than those in the MA and BA groups. The time duration of intubation and the duration of lateral recumbency were also longer in the MBA groups than those in the MA and BA groups. There were no significant differences in the standing time among 
Table 1. Sedative and cardiorespiratory effects produced by premedication with an intramuscular (IM) administration of medetomidine $(5 \mu \mathrm{g} / \mathrm{kg})$ alone, butorphanol $(0.3 \mathrm{mg} / \mathrm{kg})$ alone, or combination of both in dogs

\begin{tabular}{|c|c|c|c|c|c|c|c|c|c|c|}
\hline \multirow{2}{*}{$\begin{array}{l}\text { Anesthetic } \\
\text { treatment }\end{array}$} & \multicolumn{2}{|c|}{ Total neuro-depressive score } & \multicolumn{2}{|c|}{ Rectal temperature $\left({ }^{\circ} \mathrm{C}\right)$} & \multicolumn{2}{|c|}{ Heart rate (beats/min) } & \multicolumn{2}{|c|}{ Respiratory rate (breaths/min) } & \multicolumn{2}{|c|}{$\begin{array}{c}\text { Non-invasive mean arterial } \\
\text { blood pressure }(\mathrm{mmHg})\end{array}$} \\
\hline & $\begin{array}{c}\text { before } \\
\text { premedication }\end{array}$ & $\begin{array}{l}\text { at } 15 \text { min after } \\
\text { premedication }\end{array}$ & $\begin{array}{c}\text { before } \\
\text { premedication }\end{array}$ & $\begin{array}{l}\text { at } 15 \text { min after } \\
\text { premedication }\end{array}$ & $\begin{array}{c}\text { before } \\
\text { premedication }\end{array}$ & $\begin{array}{l}\text { at } 15 \text { min after } \\
\text { premedication }\end{array}$ & $\begin{array}{c}\text { before } \\
\text { premedication }\end{array}$ & $\begin{array}{l}\text { at } 15 \text { min after } \\
\text { premedication }\end{array}$ & $\begin{array}{c}\text { before } \\
\text { premedication }\end{array}$ & $\begin{array}{l}\text { at } 15 \text { min after } \\
\text { premedication }\end{array}$ \\
\hline \multicolumn{11}{|c|}{ Medetomidine } \\
\hline MA-1 & $2[1,2]$ & $2[2-7]$ & $38.7[38.0-38.8]$ & $38.7[38.0-38.9]$ & $96[64-112]$ & $50[36-64]^{\mathrm{a}}$ & $26[16-36]$ & $24[16-48]$ & $142[105-183]$ & $102[100-116]$ \\
\hline MA-2.5 & $2[1,2]$ & $2[1-3]$ & $38.4[37.7-39.4]$ & $38.8[37.5-39.1]$ & $96[80-108]$ & $60[44-72]^{\mathrm{a}}$ & $20[16-40]$ & $20[16-40]$ & $119[89-158]$ & $116[103-166]$ \\
\hline MA-5 & $2[1,2]$ & $2.5[1-4]$ & $38.6[38.3-39.1]$ & $38.8[37.8-39.1]$ & $72[64-108]$ & $47[34-56]^{\mathrm{a}}$ & $39[20-80]$ & $24[16-36]$ & $129[100-152]$ & $113[95-150]$ \\
\hline \multicolumn{11}{|l|}{ Butorphanol } \\
\hline BA-1 & $2[1,2]$ & $3.5[3-5]$ & $38.6[38.2-39.0]$ & $38.7[38.1-39.2]$ & $102[72-124]$ & $82[68-100]$ & $28[24-96]$ & 22 [16-92] & $120[89-141]$ & 92 [82-99] \\
\hline BA-2.5 & $2[2,2]$ & $4[2-7]$ & $38.7[38.1-39.1]$ & $38.9[38.0-39.2]$ & $92[72-124]$ & $79[68-104]$ & $37[20-56]$ & 24 [16-24] & $112[92-151]$ & $96[86-115]$ \\
\hline BA-5 & $2[2,2]$ & $2[2-6]$ & $38.7[38.4-39.0]$ & $38.7[38.4-39.2]$ & 96 [88-124] & $88[68-116]$ & 34 [24-92] & $22[12-48]$ & $121[101-140]$ & $99[80-111]$ \\
\hline \multicolumn{11}{|c|}{ Medetomidine and Butorphanol } \\
\hline MBA-1 & $2[1,2]$ & $12.5[9-15]^{\mathrm{a}}$ & $39.0[38.7-39.9]$ & $39.0[38.1-39.4]$ & $128[80-144]$ & $46[40-72]^{\mathrm{a}}$ & $40[28-96]$ & $14[8-20]^{\mathrm{a}}$ & $121[104-144]$ & $105[97-158]$ \\
\hline MBA-2.5 & $2[1,2]$ & $11.5[3-13]^{\mathrm{a}}$ & $38.8[38.0-39.0]$ & $38.6[38.3-39.0]$ & $116[88-164]$ & $48[32-60]^{\mathrm{a}}$ & $38[20-44]$ & $18[12-32]^{\text {a }}$ & $106[92-124]$ & $115[54-121]$ \\
\hline
\end{tabular}

Data was reported as median [minimum-maximum] caliculated from 6 dogs. MA-1: the dogs were premedicated with medetomidine at $5 \mu \mathrm{g} / \mathrm{kg}$ IM and then received alfaxalone at $1 \mathrm{mg} / \mathrm{kg}$ IM. MA-2.5: the dogs were premedicated with medetomidine at $5 \mu \mathrm{g} / \mathrm{kg}$ IM and then received alfaxalone at $2.5 \mathrm{mg} / \mathrm{kg}$. MA-5: the dogs were premedicated with medetomidine at $5 \mu \mathrm{g} / \mathrm{kg}$ IM and then received alfaxalone at $5 \mathrm{mg} / \mathrm{kg}$ IM. BA-1: the dogs were premedicated with butorphanol at $0.3 \mathrm{mg} / \mathrm{kg}$ IM and then received alfaxalone at $1 \mathrm{mg} / \mathrm{kg}$ IM. BA-2.5: the dogs were premedicated with butorphanol at $0.3 \mathrm{mg} / \mathrm{kg} \mathrm{IM}$ and then received alfaxalone at $2.5 \mathrm{mg} / \mathrm{kg}$ IM. BA-5: the dogs were premedicated with butorphanol at $0.3 \mathrm{mg} / \mathrm{kg}$ IM and then received alfaxalone at $5 \mathrm{mg} / \mathrm{kg}$ IM. MBA-1: the dogs were premedicated with medetomidine at $5 \mu \mathrm{g} / \mathrm{kg}$ and butorphanol at $0.3 \mathrm{mg} / \mathrm{kg} \mathrm{IM}$ and then received alfaxalone at $1 \mathrm{mg} / \mathrm{kg}$ IM. MBA-2.5: the dogs were premedicated with medetomidine at $5 \mu \mathrm{g} / \mathrm{kg}$ and butorphanol at $0.3 \mathrm{mg} / \mathrm{kg}$ IM and then received alfaxalone at $2.5 \mathrm{mg} / \mathrm{kg}$. MBA-5: the dogs were premedicated with medetomidine at $5 \mu \mathrm{g} / \mathrm{kg}$ and butorphanol at $0.3 \mathrm{mg} / \mathrm{kg}$ IM and then received alfaxalone at $5 \mathrm{mg} / \mathrm{kg}$ IM. Significant difference from the data recorded before the premedication: a) $P<0.05$.

Table 2. Times related to anesthetic effect after intramuscular (IM) dose of alfaxalone in premedicaded dogs

\begin{tabular}{|c|c|c|c|c|c|}
\hline Anesthetic treatment & $\begin{array}{l}\text { Time until lateral } \\
(\mathrm{sec})\end{array}$ & $\begin{array}{c}\text { Time until } \\
\text { intubation (min) }\end{array}$ & $\begin{array}{l}\text { Duration of intubation } \\
\text { (min) }\end{array}$ & $\begin{array}{l}\text { Duration of lateral } \\
\text { recumbency (min) }\end{array}$ & $\begin{array}{l}\text { Standing time } \\
(\mathrm{min})\end{array}$ \\
\hline \multicolumn{6}{|l|}{ Medetomidine } \\
\hline MA-1 & $262[150-915](6)$ & N. D. (0) & N. D. (0) & $41[16-60](6)$ & $2[0-26](6)$ \\
\hline MA-2.5 & $245[141-630](6)$ & 12 [12-17] (4) & 34 [28-34] (4) & $52[35-86](6)$ & $1[0-30](6)$ \\
\hline MA-5 & $113[70-175](6)^{a, b}$ & $9.5[7-14](6)$ & $50[34-82](6)$ & $85[43-126](6)^{\text {a }}$ & $4[1-9](6)$ \\
\hline \multicolumn{6}{|l|}{ Butorphanol } \\
\hline BA-1 & $1,000[276-1,250](4)$ & N. D. (0) & N. D. (0) & $1[0-42](6)$ & $0[0-0](6)$ \\
\hline BA-2.5 & $209[165-990](6)$ & $15[7-18](4)$ & $19[0-50](4)$ & $49[30-72](6)^{d}$ & $1[0-2](6)$ \\
\hline BA-5 & $311[115-440](6)^{\mathrm{c}}$ & $10[8-23](4)$ & $67[0-81](4)$ & $83[56-118](6)^{d, e}$ & $1[0-9](6)$ \\
\hline \multicolumn{6}{|c|}{ Medetomidine and Butorphanol } \\
\hline MBA-1 & $0[0-105](6)^{\text {aa, d }}$ & $8[4-13](6)$ & 82 [57-89] (6) & $89[61-92](6)^{a, d}$ & $1[0-91](6)$ \\
\hline MBA-2.5 & $0[0-180](6)^{\mathrm{b}, \mathrm{e}}$ & $7.5[4-13](6)^{b}$ & $97[84-120](6)^{b}$ & $105[90-130](6)^{\mathrm{b}, \mathrm{e}}$ & $1[0-35](6)$ \\
\hline MBA-5 & $0[0-0](6)^{\mathrm{cc}, \mathrm{ff}}$ & $6[3-7](6)^{c, f}$ & $116[84-217](6)^{\mathrm{c}, g}$ & $122[90-220](6)^{f, g}$ & $1[0-28](6)$ \\
\hline
\end{tabular}

Data was reported as median [minimum-maximum] and the number of dogs used to calculate the median was shown in parentheses. N. D.: not done. Time until onset to lateral recumbency: time from the IM administration of alfaxalone to the onset of lateral recumbency. Time until intubation: time from the IM administration of alfaxalone to the achievement of endotracheal intubation. Duration of intubation: time from the achievement of intubation to the removal of endotracheal tube. Duration of lateral recumbency: from the onset of lateral recumbency to head lift. Standing time: time from head lift to standing position. See the explanation in regarding nine anesthesia treatments in Table 1 . Significant difference from MA-1: a) $P<0.05$, aa) $P<0.01$. Significant difference from MA-2.5: b) $P<0.05$. Significant difference from MA-5: c) $P<0.05$, cc) $P<0.01$. Significant difference from BA-1: d) $P<0$.05. Significant difference from BA-2.5: e) $P<0.05$. Significant difference from BA-5: f) $P<0.05$, ff) $P<0.01$. Significant difference from MBA-1: g) $P<0.05$.

the anesthetic treatments.

The median [minimum-maximum] recovery scores were 4 [4, 4] for MA-1, MA-2.5, MA-5, and MBA-2.5; 4 [2-4] for BA-1, BA-2.5, MBA-1, and MBA-5; and 3 [2-4] for BA-5. There were no significant differences in the recovery score among the groups.

Figure 1 shows the total neuro-depressive score-time profiles. Alfaxalone administration produced a rapid and dose-dependent increase in the total neuro-depressive score. MBA-IM produced synergic increases in the total neuro-depressive score as compared with MA-IM and BA-IM. The median of the total neuro-depressive score reached the maximum (19) in MBA-5 at 10-20 min after alfaxalone administration. The median of the total neuro-depressive score (>17) was achieved at 15-20 min in MA-2.5, at 5-15 min in MBA-1, at 5-30 min in MA-5 and MBA-2.5, and at 5-45 min in MBA-5. The median value of the total neuro-depressive score was higher and longer according to alfaxalone dose. The MBA-IM groups maintained a higher total neuro-depressive score than the MA-IM and BA-IM groups. The details of each categorical score are shown in the Supplementary Fig. 1. 
Changes in cardiorespiratory valuables produced by IM alfaxalone after premedication

Tables 3 and 4 summarize the changes in cardiorespiratory valuables in dogs that received alfaxalone following premedication. Some cardiorespiratory valuables were not recorded because of a very light sedative level or awakening. After alfaxalone administration, the RT decreased gradually in a similar manner in all treatments. As mentioned above, significant decreases in the HR and bradycardia (HR $<60$ beats $/ \mathrm{min}$ ) were observed in dogs that received medetomidine alone and medetomidine-butorphanol, and bradycardia persisted even after alfaxalone administration. No dog developed hypotension (NMABP $<60 \mathrm{mmHg}$ ) in any anesthetic treatment following alfaxalone administration. $\mathrm{RR}$ decreased after alfaxalone administration in all anesthetic treatments. $\mathrm{SpO}_{2}$ could not be measured in dogs that received BA-1 treatment because of their very light sedation level. Mild hypoxemia $\left(90 \% \leq \mathrm{SpO}_{2}<95 \%\right)$ was detected in 3, 2, and 4 dogs that received MA-1, MA-2.5, and MA-5, respectively; in 5 and 6 dogs that received BA-2.5 and BA-5, respectively; and in 4, 6, and 3 dogs that received MBA-1, MBA2.5 , and MBA-5, respectively. Severe hypoxemia $\left(\mathrm{SpO}_{2}<90 \%\right)$ developed in 2 dogs that received MBA-5 treatment. There were no significant differences between the treatments in the incidence of these hypoxemias. $\mathrm{ETCO}_{2}$ was not measured in the dogs that received MA-1 and BA-1 treatments because no dogs accepted the endotracheal intubation. Mild hypercapnia $\left(45<\mathrm{ETCO}_{2} \leq 50 \mathrm{~mm} \mathrm{Hg}\right)$ was detected in a dog that received MA-5 treatment.

\section{DISCUSSION}

Intramuscular administration of alfaxalone was able to provide a dose-dependent anesthetic effect and smooth recovery in dogs when administered after IM premedication with $5 \mu \mathrm{g} / \mathrm{kg}$ medetomidine alone, $0.3 \mathrm{mg} / \mathrm{kg}$ butorphanol alone, or a combination of the two drugs. The alfaxalone dose required for induction and adequate neuro-depressive effect was $\geq 2.5 \mathrm{mg} / \mathrm{kg}$ for MA-IM and BA-IM and $\geq 1 \mathrm{mg} / \mathrm{kg}$ for MBA-IM. The MBA-IM anesthetic protocol produced rapid anesthetic induction, thereby allowing endotracheal intubation and resulting in a strong neuro-depressive effect in a dose-dependent manner, as compared with MA-IM and BA-IM. Although MBA-IM produced a better quality of anesthetic induction than MA-IM and BA-IM, some dogs with alfaxalone $5 \mathrm{mg} / \mathrm{kg}$ in MBA-IM had severe hypoxemia. We consider that the MBA-IM protocol using 1-2.5 mg/ $\mathrm{kg}$ alfaxalone could provide clinically useful and effective anesthesia without causing severe cardiorespiratory depression in healthy dogs.

The composite measurement scoring system and the total neuro-depression score employed in the present study have been previously used to evaluate sedative effect in dogs [5, 23, 27]. In the present study, $5 \mu \mathrm{g} / \mathrm{kg}$ medetomidine alone (median score $\leq 2.5$ ) or $0.3 \mathrm{mg} / \mathrm{kg}$ butorphanol alone (median score $\leq 4$ ) produced inadequate sedation, whereas combined $5 \mu \mathrm{g} / \mathrm{kg}$ medetomidine and $0.3 \mathrm{mg} / \mathrm{kg}$ butorphanol IM premedication produced adequate sedation with a remarkable increase in the total neuro-depression score (median score $\geq 11.5$ ) in $15 \mathrm{~min}$. Therefore, the neurodepression score was improved by the synergic effect of using a combination of medetomidine and butorphanol. The increase in the total neuro-depression score produced by medetomidine-butorphanol was similar to the score produced by IM administration of $10-20 \mu \mathrm{g} / \mathrm{kg}$ medetomidine alone in dogs [27]. In contrast to the synergic sedative effect, $5 \mu \mathrm{g} / \mathrm{kg}$ medetomidine and $0.3 \mathrm{mg} /$ $\mathrm{kg}$ butorphanol caused cardiorespiratory depressions that were comparable to those observed in the case of $5 \mu \mathrm{g} / \mathrm{kg}$ medetomidine alone, such as a clinically acceptable decrease in HR and RR. Our results agreed with those of previous reports, where dogs were administered low-dose IM or IV medetomidine in combination with butorphanol $[5,19]$.

Tamura et al. [24] reported that IM administration of alfaxalone alone produced a dose-dependent anesthetic induction effect that enabled endotracheal intubation at $\geq 7.5 \mathrm{mg} / \mathrm{kg}(0.75 \mathrm{ml} / \mathrm{kg})$ in dogs. In this study, the authors suggested that the volume of this dose was too large for IM administration. Maddern et al. [12] reported that a combination of $4 \mu \mathrm{g} / \mathrm{kg}$ medetomidine and $0.1 \mathrm{mg} /$ $\mathrm{kg}$ butorphanol reduced the anesthetic induction dose of IV alfaxalone compared with either agent alone in dogs; the mean doses of 


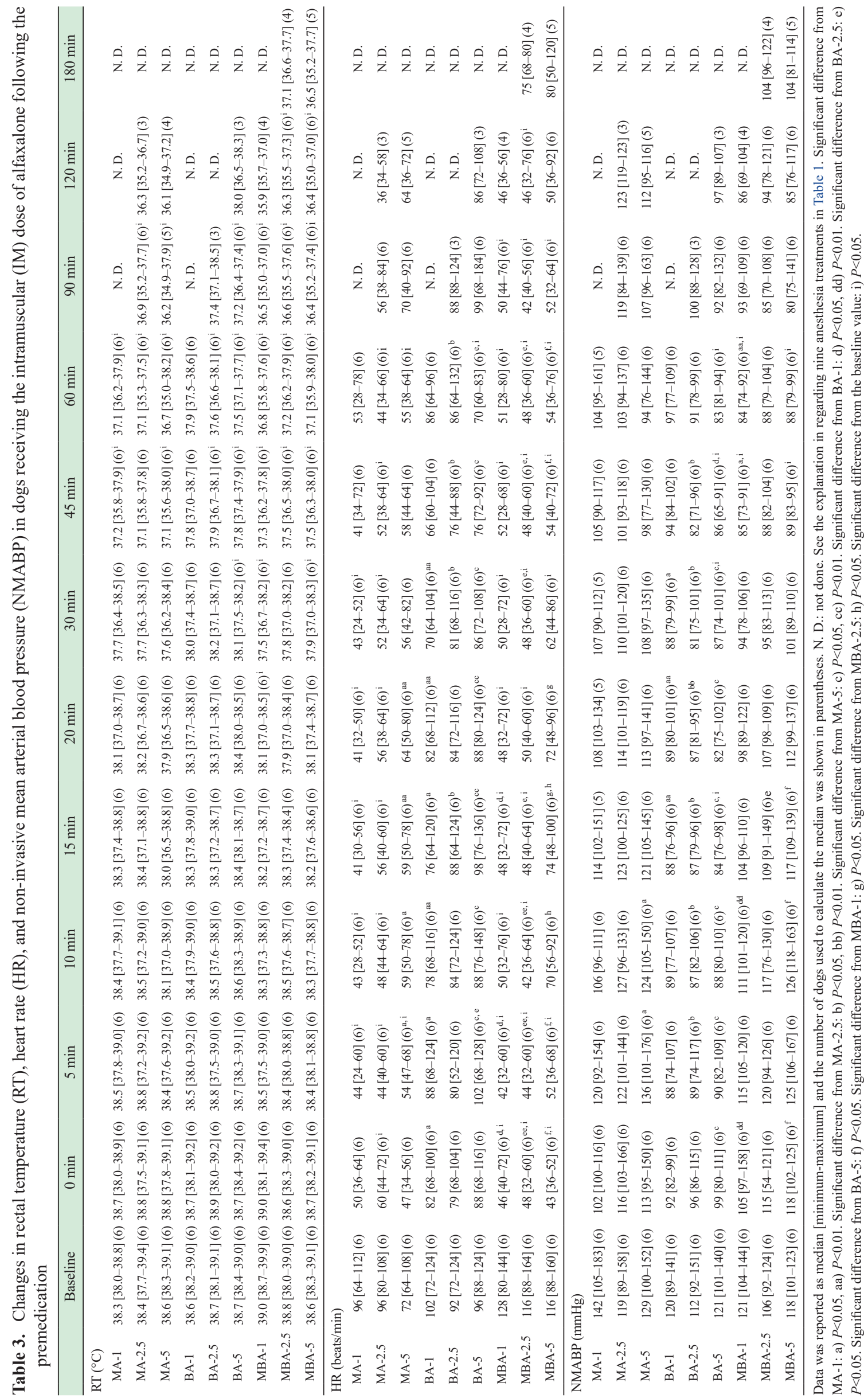




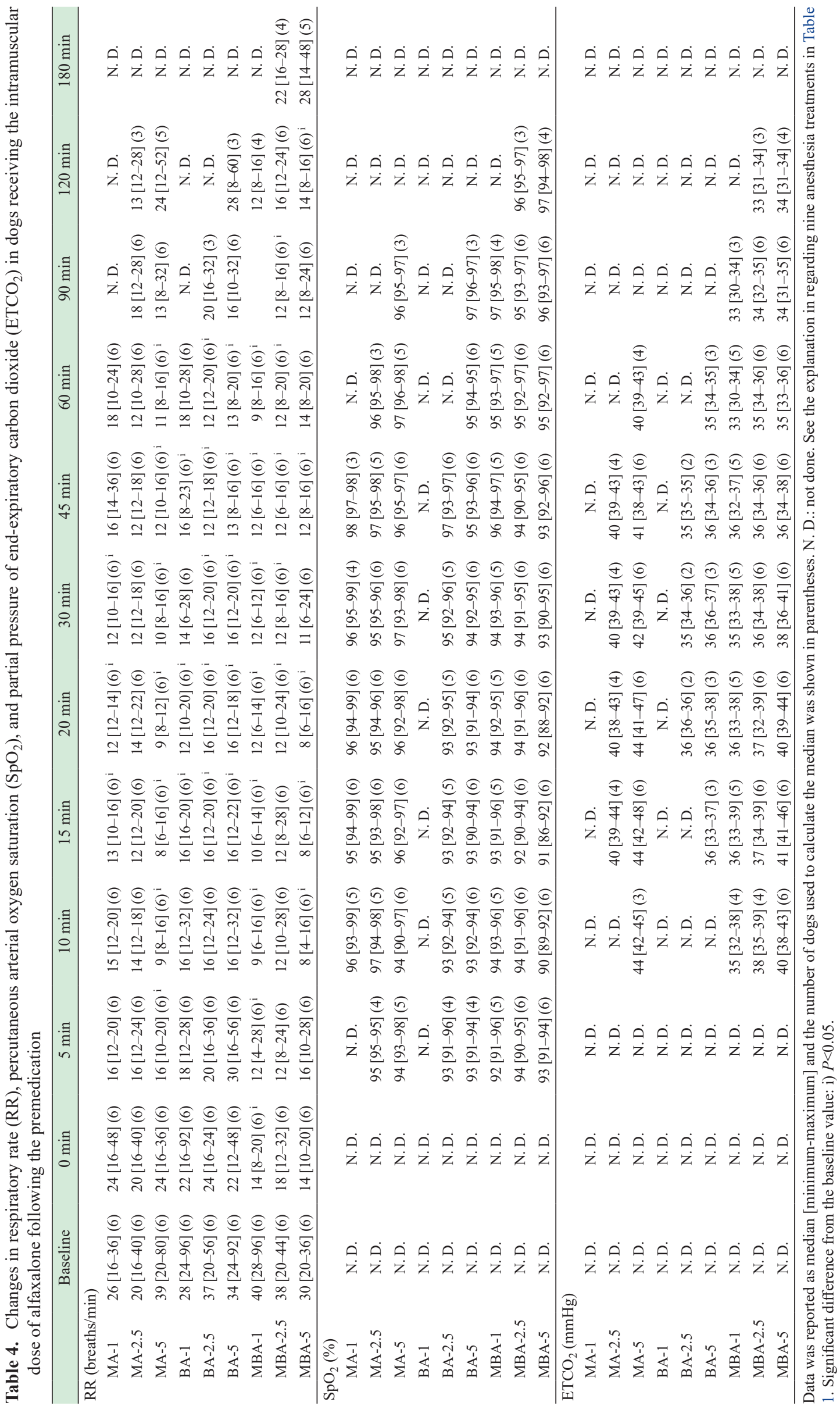


alfaxalone required for induction were $1.2 \mathrm{mg} / \mathrm{kg}$ for medetomidine or butorphanol alone and $0.8 \mathrm{mg} / \mathrm{kg}$ for a combination of both. In the present study, we examined the appropriate anesthetic induction dose of alfaxalone via intramuscular administration; the alfaxalone dose required for induction was achieved in all MBA-IM protocols. In other words, intramuscular administration of 1 $\mathrm{mg} / \mathrm{kg}$ alfaxalone following $5 \mu \mathrm{g} / \mathrm{kg}$ medetomidine and $0.3 \mathrm{mg} / \mathrm{kg}$ butorphanol could provide anesthetic effects comparable to those reported previously [12]. In addition, MBA-IM produced a better quality of anesthetic induction than MA-IM and BA-IM, and these results were also consistent with previous reports [12]. Thus, MBA-IM might produce the largest sparing effect of alfaxalone with a better quality of anesthetic induction that enabled endotracheal intubation by a synergic effect produced by a combination of low-dose medetomidine and butorphanol.

MBA-IM showed a prolonged dose-dependent anesthetic effect and produced a significant increase in the total neuro-depressive score as compared with MA-IM and BA-IM. Lee et al. [11] reported that co-administration of $10 \mu \mathrm{g} / \mathrm{kg}$ medetomidine, $0.1 \mathrm{mg} / \mathrm{kg}$ butorphanol, and $1.5 \mathrm{mg} / \mathrm{kg}$ alfaxalone produced anesthetic effects such that the dogs were able to accept endotracheal intubation for $89 \mathrm{~min}$. Tamura et al. [23] reported that co-administration of $2.5 \mu \mathrm{g} / \mathrm{kg}$ medetomidine, $0.25 \mathrm{mg} / \mathrm{kg}$ butorphanol, and $2.5 \mathrm{mg} / \mathrm{kg}$ alfaxalone produced an anesthetic effect such that 5 out of 6 healthy dogs were able to accept endotracheal intubation for 60 min. As compared to these previous reports, in our study, we inferred that MBA with alfaxalone at $1-2.5 \mathrm{mg} / \mathrm{kg}$ might produce similar anesthetic and cardiorespiratory effects as well as those previous reports [11,23]. In addition, 4 out of 6 dogs in the MA-IM and BA-IM protocols with $2.5 \mathrm{mg} / \mathrm{kg}$ alfaxalone IM were able to accept endotracheal intubation. It was considered that the present results could serve as a guide in determining the dose of alfaxalone for dogs in which medetomidine or butorphanol could not be used, as described above.

In the present study, clinically relevant bradycardia was observed in dogs that received MA-IM and MBA-IM, but no hypotension was observed in any dog. Pypendop et al. [20] reported that low-dose IV medetomidine induced dose-dependent cardiovascular depression, including transient hypertension, baroreceptor mediated bradycardia, and decreased cardiac output followed by initial peripheral vasoconstriction. As mentioned above, the combination of low-dose IM medetomidine and butorphanol provided synergic sedation without worsening the cardiorespiratory depression caused by low-dose medetomidine alone [5]. Thus, in our study, the bradycardia in dogs that received MA-IM and MBA-IM was most likely caused by a baroreceptor-mediated reflex response associated with medetomidine administration [10, 20, 22].

Hypoxemia associated with the decrease in RR was observed in all dogs that received the MA-IM, BA-IM, and MBA-IM protocols even though each dog maintained spontaneous breathing. Tamura et al. [24] reported that hypoxemia associated with a decrease in RR was observed in a dose-dependent manner following the IM administration of 5, 7.5, and $10 \mathrm{mg} / \mathrm{kg}$ alfaxalone, while the cardiovascular status was well-maintained. In contrast, Maney [13] reported that low IM doses of alfaxalone alone at 1 and $2 \mathrm{mg} / \mathrm{kg}$ produced no change in RR in dogs, and Cruz-Benedetti et al. [1] reported that there were no significant changes in oxygenation even though the RR decreased significantly in dogs that received $4 \mathrm{mg} / \mathrm{kg}$ alfaxalone IM. Lee et al. [11] reported that a combination of $10 \mu \mathrm{g} / \mathrm{kg}$ medetomidine, $0.1 \mathrm{mg} / \mathrm{kg}$ butorphanol, and $1.5 \mathrm{mg} / \mathrm{kg}$ alfaxalone caused severe hypoxemia associated with a decrease in RR in healthy dogs. Tamura et al. [23] reported that the combination of $2.5 \mu \mathrm{g} / \mathrm{kg}$ medetomidine, $0.25 \mathrm{mg} /$ $\mathrm{kg}$ butorphanol, and $2.5 \mathrm{mg} / \mathrm{kg}$ alfaxalone caused a significant decrease in RR without clinically relevant hypoxemia in healthy dogs. In our study, the hypoxemia might have been caused by hypoventilation due to a decrease in RR associated with alfaxalone administration or by synergic respiratory depression associated with low-dose medetomidine and butorphanol administration.

Vomiting is a well-known side effect of medetomidine and was observed in $8-20 \%$ of dogs that received moderate and high doses of medetomidine in a previous study [22]. In the present study, no dog exhibited vomiting after receiving $5 \mu \mathrm{g} / \mathrm{kg}$ medetomidine alone and in combination with $0.3 \mathrm{mg} / \mathrm{kg}$ butorphanol. The occurrence of vomiting in dogs that received low-dose IV (1-2.5 $\mu \mathrm{g} /$ $\mathrm{kg}$ ) medetomidine alone has not been documented [5, 19]. In addition, butorphanol produced central antiemetic properties through the opioid receptor and effectively reduced the vomiting induced by medetomidine [6]. We speculate that low-dose medetomidine might cause lesser vomiting, and the co-administration of low-dose medetomidine and butorphanol might prevent medetomidineinduced vomiting. Meanwhile, 3 dogs had salivation after administration of butorphanol alone. The package insert of butorphanol states that salivation may be permitted. Although it was difficult to distinguish whether salivation was associated with nausea or not, parasympathetic stimulation by butorphanol might cause serous salivation from the salivary glands [17].

Adverse effects, such as involuntary muscle tremors and transient ataxia, have been reported during the recovery period in dogs receiving IM alfaxalone alone $[13,24]$. Meanwhile, there was a report that the quality of recovery after co-administration of medetomidine, butorphanol, and alfaxalone was better and had less undesirable events as compared with IM alfaxalone alone [23, 24]. Premedication with buprenorphine and acepromazine [8] or co-administration of dexmedetomidine [21] reportedly improves the quality of recovery from total intravenous anesthesia with alfaxalone in dogs. These findings indicate that premedication or co-administration of sedative and analgesic drugs may improve the quality of recovery from alfaxalone anesthesia. In the present study, almost all the dogs recovered rapidly and smoothly from each anesthetic protocol following their head lift. Particularly, alfaxalone administration for dogs with low-dose of medetomidine with or without butorphanol showed good recovery. Using lowdose medetomidine or butorphanol alone and in combination with alfaxalone might be related to lower occurrence of undesirable events during the recovery period.

A limitation this study has is that premedication and alfaxalone were not administered at the same time. The European Federation of Pharmaceutical Industries Associations and the European Centre for the Validation of Alternative Methods provide a guideline for the administration of IM volumes [3]. The reported IM volume considered as good practice is $0.25 \mathrm{ml} / \mathrm{kg}$, and the maximal dose volume is $0.5 \mathrm{ml} / \mathrm{kg}$ in dogs [3]. This is to avoid discomfort in animals due to the large volume of the drugs (i.e., $>0.5 \mathrm{ml} / \mathrm{kg}$; BA-5, MA-5, and MBA-5) in this study. Therefore, we could not determine whether the same results could be obtained 
if these drugs were administered at the same time. However, from the results of this study, a dose of alfaxalone $1-2.5 \mathrm{mg} / \mathrm{kg}$ (i.e., almost $0.1-0.25 \mathrm{ml} / \mathrm{kg}$ ) was required to obtain an anesthetic effect in combination with medetomidine and/or butorphanol. Further studies are needed to establish the anesthetic and cardiorespiratory effects of the co-administration of these drugs.

In conclusion, a dose-dependent anesthetic effect with alfaxalone and smooth recovery was provided by IM alfaxalone following IM premedication with low-dose medetomidine $(5 \mu \mathrm{g} / \mathrm{kg})$ alone, butorphanol $(0.3 \mathrm{mg} / \mathrm{kg})$ alone, and a combination of both. The dose of alfaxalone required for induction and adequate neuro-depressive effect was $\geq 2.5 \mathrm{mg} / \mathrm{kg}$ for MA-IM and BA-IM. We also considered that the MBA-IM protocol using $1-2.5 \mathrm{mg} / \mathrm{kg}$ alfaxalone could provide clinically useful and effective anesthesia without causing severe cardiorespiratory depression in healthy dogs.

POTENTIAL CONFLICTS OF INTEREST. The authors have nothing to disclose.

\section{REFERENCES}

1. Cruz-Benedetti, I. C., Bublot, I., Ribas, T., Fourel, I., Vogl, C., Dubois, C., Milani, M., Ida, K. K. and Portier, K. 2018. Pharmacokinetics of intramuscular alfaxalone and its echocardiographic, cardiopulmonary and sedative effects in healthy dogs. PLoS One 13: e204553. [Medline] [CrossRef]

2. Davies, P. 2014. GABAA receptor genetics and clinical pharmacology. Curr. Anesthesiol. Rep. 4: 42-48. [CrossRef]

3. Diehl, K. H., Hull, R., Morton, D., Pfister, R., Rabemampianina, Y., Smith, D., Vidal, J. M., van de Vorstenbosch C., European Federation of Pharmaceutical Industries Association and European Centre for the Validation of Alternative Methods. 2001. A good practice guide to the administration of substances and removal of blood, including routes and volumes. J. Appl. Toxicol. 21: 15-23. [Medline] [CrossRef]

4. Ferré, P. J., Pasloske, K., Whittem, T., Ranasinghe, M. G., Li, Q. and Lefebvre, H. P. 2006. Plasma pharmacokinetics of alfaxalone in dogs after an intravenous bolus of Alfaxan-CD RTU. Vet. Anaesth. Analg. 33: 229-236. [Medline] [CrossRef]

5. Girard, N. M., Leece, E. A., Cardwell, J., Adams, V. J. and Brearley, J. C. 2010. The sedative effects of low-dose medetomidine and butorphanol alone and in combination intravenously in dogs. Vet. Anaesth. Analg. 37: 1-6. [Medline] [CrossRef]

6. Hayashi, K., Nishimura, R., Yamaki, A., Kim, H., Matsunaga, S., Sasaki, N. and Takeuchi, A. 1994. Comparison of sedative effects induced by medetomidine, medetomidine-midazolam and medetomidine-butorphanol in dogs. J. Vet. Med. Sci. 56: 951-956. [Medline] [CrossRef]

7. Hellebrekers, L. J., Sap, R. and van Wandelen, R. M. 1990. [Intramuscularly administered non-opiate anesthesia in dogs. A report on the use of ketamine/xylazine, tiletamine/zolazepam, ketamine/midazolam and metomidine]. Tijdschr. Diergeneeskd. 115: 661-669. [Medline]

8. Herbert, G. L., Bowlt, K. L., Ford-Fennah, V., Covey-Crump, G. L. and Murrell, J. C. 2013. Alfaxalone for total intravenous anaesthesia in dogs undergoing ovariohysterectomy: a comparison of premedication with acepromazine or dexmedetomidine. Vet. Anaesth. Analg. 40: 124-133. [Medline] [CrossRef]

9. Keates, H. and Whittem, T. 2012. Effect of intravenous dose escalation with alfaxalone and propofol on occurrence of apnoea in the dog. Res. Vet. Sci. 93: 904-906. [Medline] [CrossRef]

10. Kuo, W. C. and Keegan, R. D. 2004. Comparative cardiovascular, analgesic, and sedative effects of medetomidine, medetomidine-hydromorphone, and medetomidine-butorphanol in dogs. Am. J. Vet. Res. 65: 931-937. [Medline] [CrossRef]

11. Lee, J., Suh, S., Choi, R. and Hyun, C. 2016. Cardiorespiratory and anesthetic effects produced by the combination of butorphanol, medetomidine and alfaxalone administered intramuscularly in Beagle dogs. J. Vet. Med. Sci. 77: 1677-1680. [Medline] [CrossRef]

12. Maddern, K., Adams, V. J., Hill, N. A. and Leece, E. A. 2010. Alfaxalone induction dose following administration of medetomidine and butorphanol in the dog. Vet. Anaesth. Analg. 37: 7-13. [Medline] [CrossRef]

13. Maney, J. K. 2017. Sedative and physiologic effects of low-dose intramuscular alfaxalone in dogs. Vet. Anaesth. Analg. 44: 1184-1188. [Medline] [CrossRef]

14. Muir, W., Lerche, P., Wiese, A., Nelson, L., Pasloske, K. and Whittem, T. 2008. Cardiorespiratory and anesthetic effects of clinical and supraclinical doses of alfaxalone in dogs. Vet. Anaesth. Analg. 35: 451-462. [Medline] [CrossRef]

15. Muir, W. W. 3rd., Ford, J. L., Karpa, G. E., Harrison, E. E. and Gadawski, J. E. 1999. Effects of intramuscular administration of low doses of medetomidine and medetomidine-butorphanol in middle-aged and old dogs. J. Am. Vet. Med. Assoc. 215: 1116-1120. [Medline]

16. Murphy, M. R. and Hug, C. C. Jr. 1982. The enflurane sparing effect of morphine, butorphanol, and nalbuphine. Anesthesiology 57: 489-492. [Medline] [CrossRef]

17. Plumb, D. C. 2015. Butorphanol tartrate. pp. 135-139. In: Plumb's Veterinary Drug Handbook, 8th ed. (Plumb, D. C. ed.), Wiley Blackwell, Ames.

18. Plumb, D. C. 2015. Medetomidine HCl. pp. 663-665. In: Plumb's Veterinary Drug Handbook, 8th ed. (Plumb, D. C. ed.), Wiley Blackwell, Ames.

19. Puighibet, Z., Costa-Farré, C., Santos, L., Canfrán, S. and Gómez de Segura, I. A. 2015. The sedative effects of intramuscular low-dose medetomidine in combination with butorphanol or methadone in dogs. Vet. Anaesth. Analg. 42: 590-596. [Medline] [CrossRef]

20. Pypendop, B. H. and Verstegen, J. P. 1998. Hemodynamic effects of medetomidine in the dog: a dose titration study. Vet. Surg. 27 : 612-622. [Medline] [CrossRef]

21. Quirós Carmona, S., Navarrete-Calvo, R., Granados, M. M., Domínguez, J. M., Morgaz, J., Fernández-Sarmiento, J. A., Muñoz-Rascón, P. and Gómez-Villamandos, R. J. 2014. Cardiorespiratory and anaesthetic effects of two continuous rate infusions of dexmedetomidine in alfaxalone anaesthetized dogs. Res. Vet. Sci. 97: 132-139. [Medline] [CrossRef]

22. Sinclair, M. D. 2003. A review of the physiological effects of alpha2-agonists related to the clinical use of medetomidine in small animal practice. Can. Vet. J. 44: 885-897. [Medline]

23. Tamura, J., Hatakeyama, N., Ishizuka, T., Itami, T., Fukui, S., Miyoshi, K., Sano, T., Pasloske, K. and Yamashita, K. 2016. The pharmacological effects of intramuscular administration of alfaxalone combined with medetomidine and butorphanol in dogs. J. Vet. Med. Sci. 78: 929-936. [Medline] [CrossRef]

24. Tamura, J., Ishizuka, T., Fukui, S., Oyama, N., Kawase, K., Miyoshi, K., Sano, T., Pasloske, K. and Yamashita, K. 2015. The pharmacological effects of the anesthetic alfaxalone after intramuscular administration to dogs. J. Vet. Med. Sci. 77: 289-296. [Medline] [CrossRef]

25. Trim, C. M. 1983. Cardiopulmonary effects of butorphanol tartrate in dogs. Am. J. Vet. Res. 44: 329-331. [Medline]

26. Ueyama, Y., Ueyema, Y., Waselau, A. C., Wiese, A. J. and Muir, W. W. 2008. Anesthetic and cardiopulmonary effects of intramuscular morphine, medetomidine, ketamine injection in dogs. Vet. Anaesth. Analg. 35: 480-487. [Medline] [CrossRef]

27. Young, L. E., Brearley, J. C., Richards, D. L. S., Bartram, D. H. and Jones, R. S. 1990. Medetomidine as a premedicant in dogs and its reversal by atipamezole. J. Small Anim. Pract. 31: 554-559. [CrossRef] 